\title{
SISTEM PEMANTAUAN PERTUMBUHAN BATITA MENGGUNAKAN METODE FUZZY TSUKAMOTO
}

\author{
Irma Anggraeni ${ }^{1)}$, Yusma Yanti ${ }^{2}$ \\ 1,2) Program Studi IImu Komputer, FMIPA, Univeristas Pakuan, Bogor, Indonesia \\ \#Corresponding Author: irmairhamna@unpak.ac.id
}

Article history: received 15 December 2019; revised 16 January 2020; accepted 25 January 2020

\begin{abstract}
Abstrak
Pertumbuhan anak bawah usia tiga tahun (batita) merupakan salah satu penentu perkembangan anak di masa depannya. Salah satu parameter penilaian pertumbuhan batita ditentukan oleh jenis kelamin, usia, tinggi badan dan berat badan. Penelitian ini membuat sebuah sistem yang dapat memantau pertumbuhan batita dengan berbasis web. Metode penelitian yang digunakan adalah System Life Development Cycle, yang terdiri atas perencanaan, analisis, desain, implementasi dan penggunaan. Sistem ini juga menggunakan metode fuzzy tsukamoto untuk menentukan himpunan keanggotaan dari setiap variabel input. Pada kriteria jenis kelamin dibagi menjadi dua kelas yaitu laki laki dan perempuan, kriteria usia dibagi dalam tiga kelas, kriteria tinggi badan tiga kelas, dan kriteria berat bedan dibagi menjadi tiga kelas. Berdasarkan pembagian kelas tersebut, keluaran dari penelitian ini adalah status pertumbuhan dari anak batita yaitu pertumbuhan buruk, kurang, normal dan lebih. Berdasarkan hasil input data kriteria serta perhitungan menggunakan fuzzy tsukamoto, maka didapat keluaran berupa status dari pertumbuhan anak tersebut.
\end{abstract}

Keywords : batita. fuzzy tsukamoto, website

\begin{abstract}
The growth of children under the age of three (toddlers) is one of the determinants of children's development in the future. One of the parameters of toddler growth assessment is determined by gender, age, height and weight. This research makes a system that can monitor toddler growth with web-based. The research method used is the System Life Development Cycle, which consists of planning, analysis, design, implementation and use. This system also uses the Tsukamoto fuzzy method to determine the membership set of each input variable. The gender criteria are divided into two classes, male and female, the age criteria are divided into three classes, the height criteria are three classes, and the weight criteria are divided into three classes. Based on the division of classes, the output of this study is the growth status of toddlers, namely poor growth, poor, normal and more. Based on the results of input data criteria and calculations using Tsukamoto fuzzy, the output obtained in the form of the status of the child's growth.
\end{abstract}

Keywords: toddler. Fuzzy Tsukamoto, website

\section{Pendahuluan}

Gagal tumbuh (growth faltering) yang tercermin dari keadaan tinggi dan berat badan kurang pada anak-anak di negara berkembang masih menjadi masalah global. Standing committee on nutrition (SCN) memperkirakan sebanyak 147,5 juta balita mengalami stunting dan 126,5 juta anak memiliki berat badan kurang menurut usianya pada tahun 2005 [1]. Sebanding dengan masalah global tersebut, sebesar $37,2 \%$ balita di Indonesia termasuk dalam kategori pendek sedangkan balita dengan berat badan kurang mencapai 19,6\% [2]. Kelompok balita yang mengalami gagal tumbuh tersebut memiliki risiko yang lebih tinggi untuk hidup dalam kemiskinan ketika dewasa karena tingkat kecerdasan yang rendah [3]. 
Untuk itu memantau pertumbuhan anak merupakan hal yang sangat penting dilakukan bagi orang tua. Beberapa faktor yang menentukan pertumbuhan anak adalah jenis kelamin, usia, berat badan, dan tinggi badan. Dengan melihat faktor tersebut maka kita dapat mengetahui kondisi pertubuhan anak tersebut. Untuk menentukan pertumbuhan anak baik atau tidak diperlukan suatu penilaian. Salah satu metode yang digunakan untuk menentukan penilaian tersebut dengan menggunakan fuzzy tsukamoto. Metode ini banyak digunakan untuk menentukan hasil berdasarkan kriteria penilaian.

Penelitian yang dilakukan oleh Suharjito untuk mendeteksi penyakit endometris [4] pada sapi dengan menggunakan metode fuzzy tsukamoto dan mendapatkan hasil akurasi dari sistem yang sama dengan diagnosis jika dilakukan oleh manusia. Ratnawati dan Fauzi [5] mengklasifikasi resiko penyakit stroke dengan menggunakan metode fuzzy tsukamoto dan optimalisasi menggunakan algoritma genetika. Oleh karena itu dalam penelitian ini dibuat sistem pemantauan pertumbuhan batita dengan menggunakan fuzzy tsukamoto sebagai perhitungan dengan berbasis website.

\section{Metode Penelitian}

Pada pembuatan serta pengembangan sistem pemantauan pertumbuhan ini secara umum menggunakan model System Develpomnet Life Cycle (SDLC) seperti pada Gambar 1.

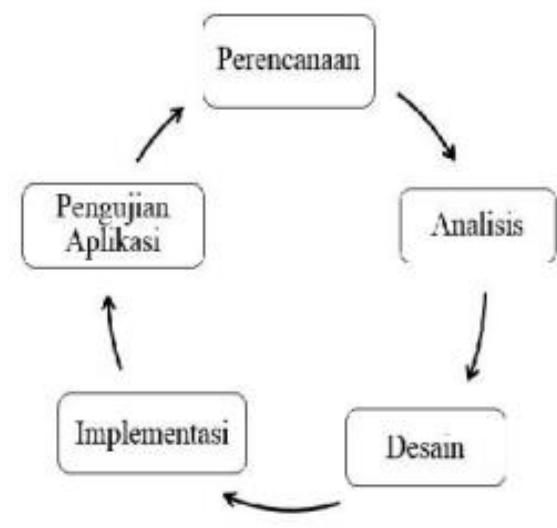

Gambar 1. Pendekatan SDLC

\subsection{Fuzzy Tsukamoto}

Logika fuzzy merupkan salah satu logika tegas, dia yang memiliki dua nilai yang jelas yaitu nilai benar atau salah. Pada teori logika fuzzy sebuah nilai dapat dianggap benar dan salah secara bersamaan, bergantung pada nilai keanggotaanya [6]. Pada himpunan fuzzy nilai keanggotaan antara 0 dan 1 . Apabila $x$ memiliki nilai 0 berarti $x$ tidak menjadi anggota himpunan A, demikian pula apabila $x$ memiliki nilai 1 berarti $x$ menjadi anggota penuh pada himpunan $A$ [7].

Logika Fuzzy adalah suatu metode yang digunakan untuk membentuk kapasitas manusia atas penalaran tidak pasti atau penalaran perkiraan. Sehingga berdasarkan penalaran tersebut mapu merepresentasikan kemampuan manusia dalam memutuskan sesuatu di bawah ketidakpastian [8].

Inferensi Fuzzy Tsukamoto merupakan proses penggabungan banyaknya aturan berdasarkan data yang ada. Suatu komponen yang melakukan inferensi dalam sistem pakar disebut dengan sistem inferensi. Pada Inferensi Fuzzy Tsukamoto, maka setiap aturan direpresentasikan menggunakan himpunan-himpunan Fuzzy, dengan fungsi keanggotaan yang monoton. Untuk nilai output crisp ( $Z$ ) dicari dengan mengubah input (berupa himpunan Fuzzy yang dapat diperoleh dari suatu komposisi aturanaturan Fuzzy ) menjadi suatu bilangan pada domain himpunan Fuzzy tersebut. Cara ini biasa disebut dengan metode defuzzifikasi. Metode defuzzifikasi yang digunakan dalam Inferensi Fuzzy Tsukamoto yaitu metode defuzzufikasi ratarata terpusat (Center Average Defuzzifier) [9]. Ada beberapa tahap untuk cara kerja [10] pada logika Fuzzy yaitu:

\section{Fuzzifikasi}


2. Membuat rule (aturan)

3. Mesin inferensi

4. Defuzzifikasi

Fuzzy Tsukamoto memiliki suatu rule yang dimana dapat menentukan bagaimana perhitungan hasil outputnya nanti. Di dalam metode penegasan yang dipakai pada inferensi Fuzzy Tsukamoto yaitu metode defuzzifikasi rata-rata terpusat (Center Average Defuzzyfier) (Lee, 2005). Berikut ini adalah rumus rule yang dipakai dalam metode ini

$$
Z=\frac{(a 1 \times z 1)(a 2 \times z 2)}{a 1+a 2}
$$

Keterangan :

$Z=$ nilai crisp output

$a 1=$ nilai keanggotaan anteseden dari aturan Fuzzy

$z 1=$ nilai output pada aturan Fuzzy

$a 2=$ nilai keanggotaan anteseden dari aturan Fuzzy

$z 2=$ nilai output pada aturan Fuzzy.

\subsection{Bawah Tiga Tahun (Batita)}

Tumbuh kembang balita merupakan serangkaian kegiatan yang berkelanjutan berupa pemenuhan kebutuhan dasar, kasih sayang, pemeliharaan kesehatan, kecukupan gizi, pemberian stimulasi dini dan pendidikan yang baik. Untuk itu diperlukan pemantauan yang tepat dan terarah agar menjamin tumbuh kembang anak lebih optimal [11].

Pada penelitian yang dilakukan oleh Arrasad [12] menyatakan cara untuk melakukan penilaian status gizi pada kelompok masyarakat salah satunya dengan pengukuran tubuh manusia yang dikenal dengan antropometri yang disajikan dalam bentuk indeks yang dikaitkan dengan variabel lain. Variabel tersebut diantarnya Umur (U), Berat Badan (BB), dan Tinggi Badan (TB).

Berat badan dan tinggi badan adalah salah satu parameter penting untuk menentukan status kesehatan manusia, khususnya yang berhubungan dengan status gizi. Penggunaaan Indeks $\mathrm{BB} / \mathrm{U}, \mathrm{TB} / \mathrm{U}$ dan BB/TB merupakan indikator status gizi untuk melihat adanya gangguan fungsi pertumbuhan dan komposisi tubuh. Penggunaan berat badan dan tinggi badan akan lebih jelas dan sensitive dalam menunjukkan keadaan gizi. Berdasarkan hal tersebut penelitian ini menggunakan kriteria jenis kelamin, berat badan dan tinggi badan sebagai parameter penilaian.

Untuk perancangan sistem ini yaitu membuat alur program secara umum dengan menggunakan metode fuzzy tsukamoto yang ditunjukan pada Gambar 2. 
KOMPUTASI (Jurnal IImiah IImu Komputer dan Matematika)

Vol. 17, No. 1, Januari 2020, Hal. $346-353$

P-ISSN: 1693-7554, E-ISSN: 2654-3990



Gambar 2. Flow chart sistem

\section{Hasil dan Pembahasan}

Perhitungan kriteria Fuzzy Tsukamoto berdasarkan kriteria yang didapat yaitu jenis kelamin, usia, berat badan dan tinggi badan berikut ini adalah aturan keanggotaan fuzzy tsukamoto ini yang ditunjukan pada tabel di bawah ini

Tabel 1. Aturan tahap 1 (0-12 bulan)

\begin{tabular}{llcc} 
& & Tinggi Badan \\
\hline Berat Badan & pendek & normal & tinggi \\
Kurus & normal & normal & kurus \\
Normal & gemuk & normal & gemuk \\
Lebih & gemuk & gemuk & gemuk \\
\hline
\end{tabular}

Tabel 2. Aturan tahap 2 (6-24 bulan)

\begin{tabular}{lccc}
\hline & \multicolumn{3}{c}{ Tinggi Badan } \\
\hline Berat Badan & Pendek & normal & tinggi \\
Kurang & Kurus & kurus & kurus \\
Normal & Normal & normal & Normal \\
Lebih & Gemuk & gemuk & gemuk \\
\hline
\end{tabular}

Sistem Pemantauan Pertumbuhan Batita Menggunakan Metode Fuzzy Tsukamoto (Irma Anggraeni, Yusma Yanti) 
Tabel 3. Aturan tahap 3 (12-36 bulan)

\begin{tabular}{lccc}
\hline & \multicolumn{3}{c}{ Tinggi Badan } \\
\hline Berat Badan & pendek & normal & tinggi \\
Kurus & buruk & buruk & buruk \\
Normal & normal & normal & normal \\
Lebih & gemuk & gemuk & gemuk \\
\hline
\end{tabular}

Berdasarkan aturan fuzzy yang telah dibuat maka diimplementasikan kedalam sistem berbasis website. Berikut ini adalah hasil tampilan sistem yang telah dibuat:

\subsection{Halaman Login}

Sistem Pemantauan pertumbuhan ini dapat diakses setelah melakukan login yang merupakan halaman utama pada sistem ini. Pada menu ini terdapat username dan password untuk dapat masuk ke halaman utama seperti yang ditunjukan pada Gambar 4.

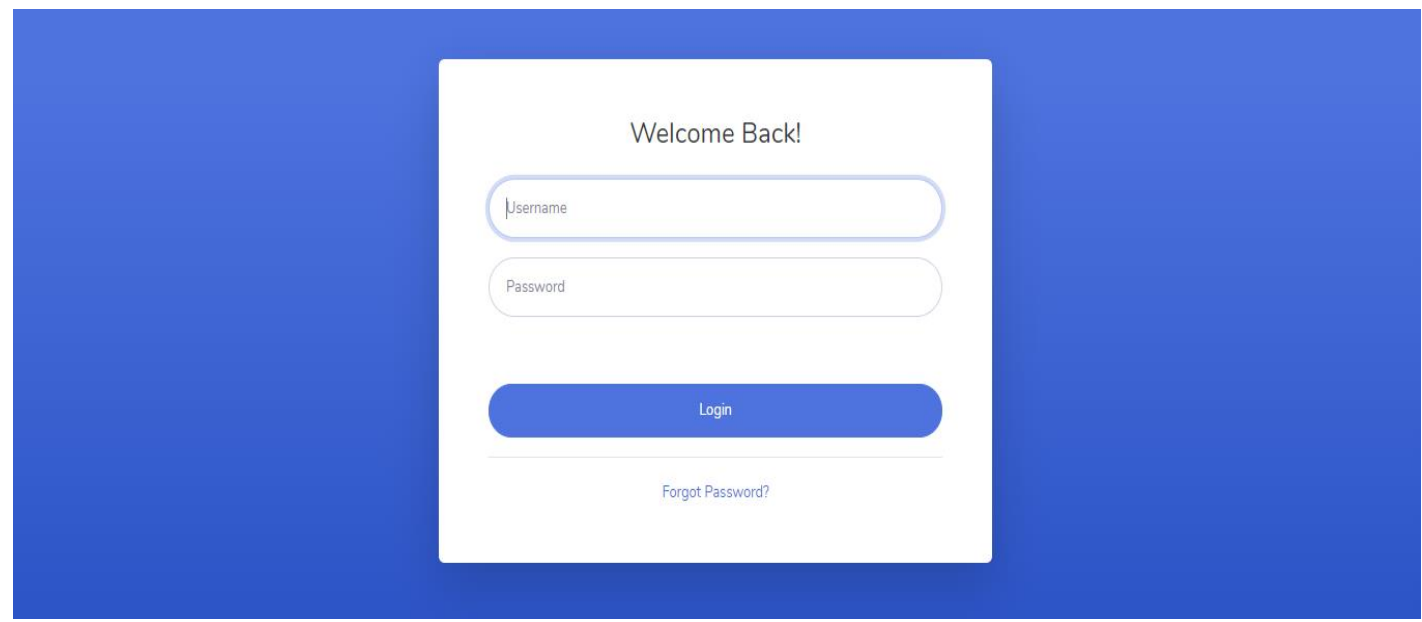

Gambar 3 Halaman login sistem

\subsection{Halaman kriteria}

Pada halaman ini berisi kriteria input pada sistem. Untuk kriteria dalam sistem ini bersifat dinamis, jika ada perubahan baik penambahan atau pengurangan maka dapat dilakukan secara langsung seperti yang ditunjukan pada Gambar 5.
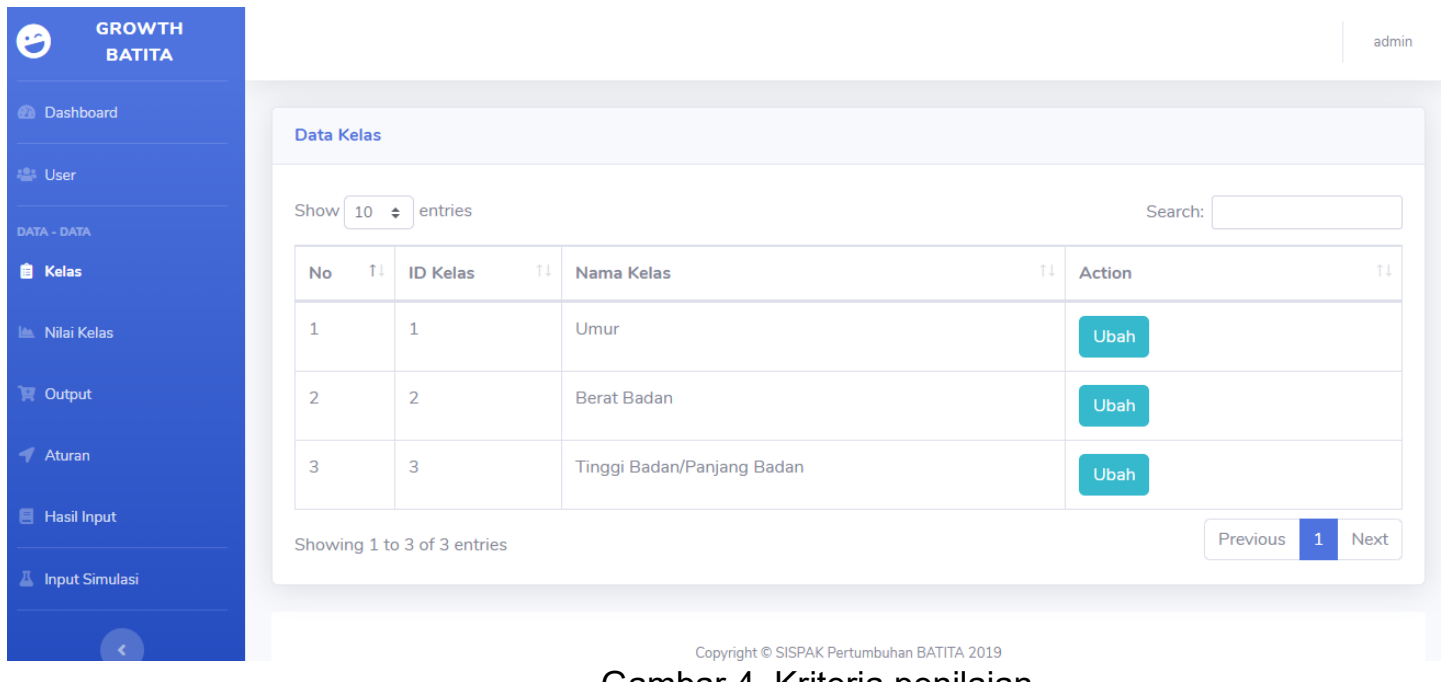

Gambar 4. Kriteria penilaian 
KOMPUTASI (Jurnal IImiah IImu Komputer dan Matematika)

Vol. 17, No. 1, Januari 2020, Hal. 346 - 353

P-ISSN: 1693-7554, E-ISSN: 2654-3990

\subsection{Halaman Keanggotaan Fuzzy}

Halaman ini berisi perhitungan keanggotaan fuzzy untuk setiap kriteria yang ada pada sistem ditunjukkan pada Gambar 6.


Gambar 5. Keanggotaan fuzzy

\subsection{Halaman Simulasi}

Halaman ini berisi simulasi perhitungan berdasarkan input kriteria pada sistem yang ditunjukkan pada Gambar 7.



Simulasi



Umur (bulan)

Berat Badan $(\mathrm{kg})$

Tinggi Badan/Panjang Badan (cm)

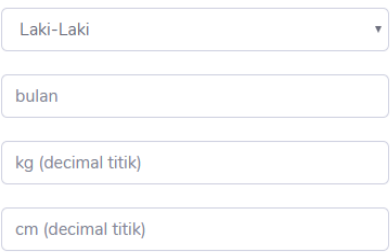

Copyright O SISPAK Pertumbuhan BATTA 2019

Gambar 6. Simulasi status pertumbuhan

\subsection{Halaman input simulasi}

Halaman ini berisi data yang telah di input ke dalam sistem berdasarkan perhitungan menggunakan fuzzy tsukamoto, maka didapatkan hasil berupa nilai pertumbuhan anak, dengan status pertumbuhan seperti yang ditunjukan pada Gambar 8 


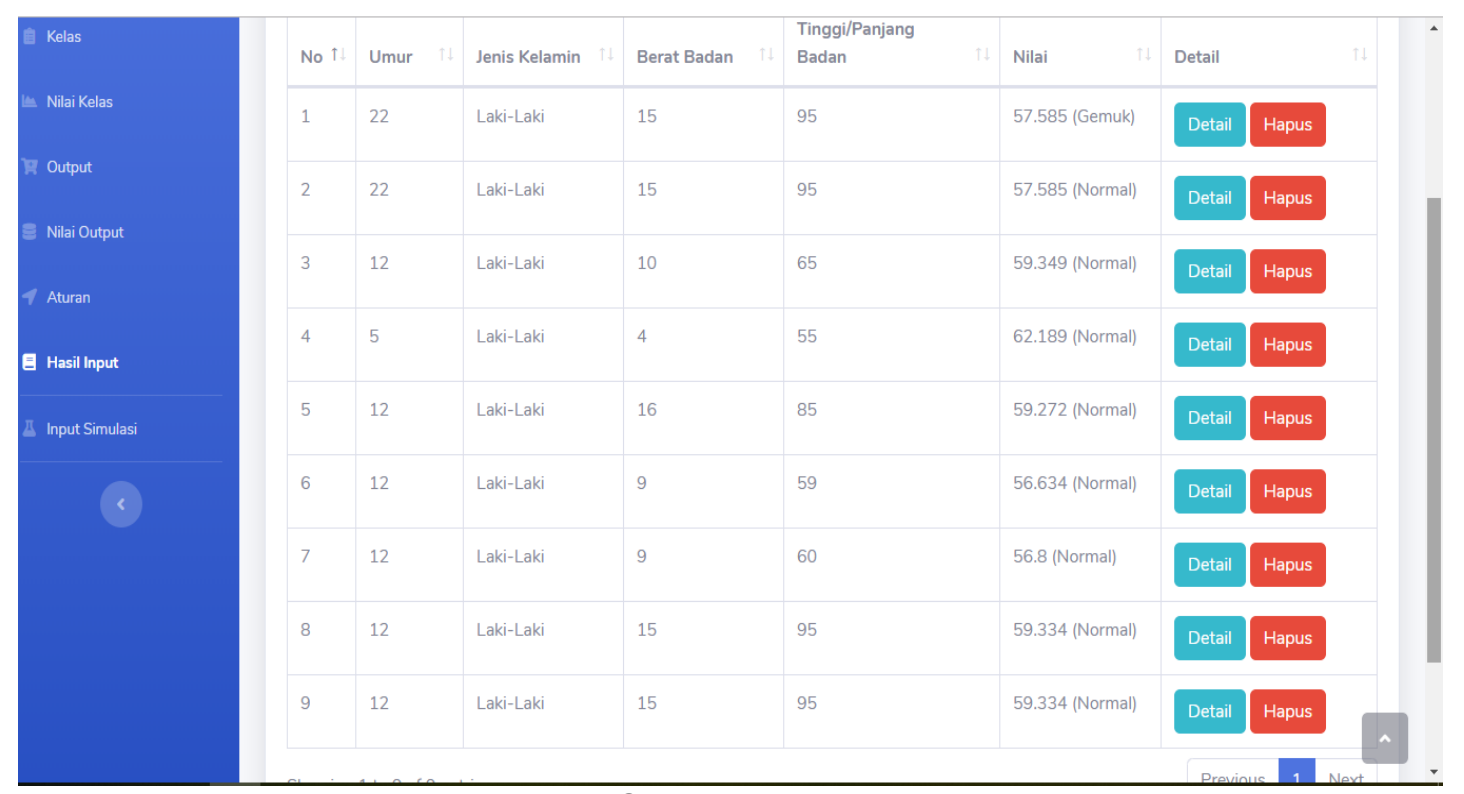

Gambar 7. hasil simulasi

\subsection{Halaman input simulasi fuzzy}

Halaman ini berisi proses perhitungan fuzzy yang dilakukan jika dimasukan data setiap kriteria. Proses perhitungan dimulai dari fuzzifikasi setiap kriteria, sampai mendapatkan nilai kemudian status pertumbuhan dari seorang anak yang ditunjukan pada Gam bar 8 di bawah ini.
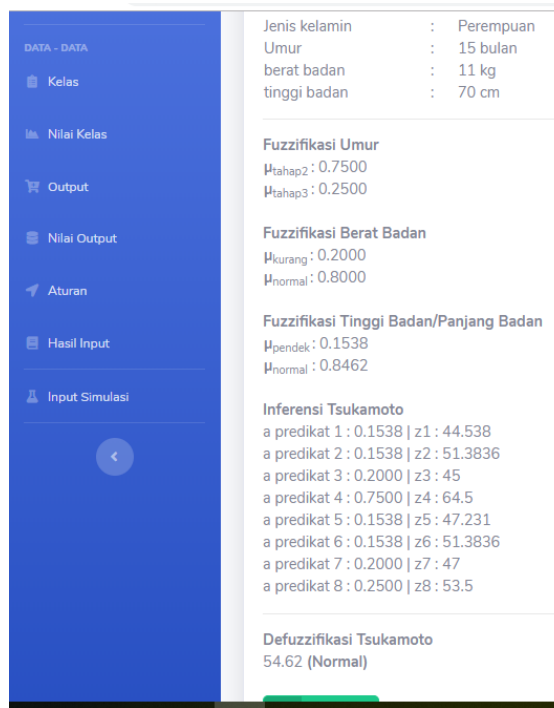

Gambar 8. proses perhitungan fuzy tsukamoto dalam sistem

Pada perhitungan sistem pemantauan pertumbuhan ini input yang dimasukan adalah jenis kelamin, usia, berat badan serta tinggi badan. Kemudian setelah itu dilakukan perhitungan bagi setiap nilai kriteria menggunakan fuzzy tsukamoto. Berdasarkan nilai dari masing masing kriteria tersebut maka akan ditentukan berada dikelas mana batita tersebut.

\section{Kesimpulan}

Berdasarkan hasil penelitian yang telah dilakukan bahwa penelitian ini menggunakan kriteria jenis kelamin, usia, berat badan, dan tinggi badan untuk menentukan pertumbuhan bagi batita. Dengan menggunakan metode fuzzy tsukmoto maka pembagian kelas setiap kriteria dapat ditentukan. Untuk berat badan dibagi menjadi kurus, normal, gemuk dan sangat gemuk. Sedangkan pada kriteria tinggi badan dibagi menjadi pendek, normal, dan tinggi. Dengan adanya sistem pemantauan pertumbuhan ini dapat membantu orang tua untuk mengtahui kondisi 
KOMPUTASI (Jurnal IImiah IImu Komputer dan Matematika)

Vol. 17, No. 1, Januari 2020, Hal. $346-353$

P-ISSN: 1693-7554, E-ISSN: 2654-3990

https://journal.unpak.ac.id/index.php/komputasi

pertumbuhan anak.

\section{Referensi}

[1] Peraturan Menteri Kesehatan Republik Indonesia Nomor 75 Tahun 2013 tentang Angka Kecukupan Gizi yang Dianjurkan bagi Bangsa Indonesia. Diakses melalui http://gizi.depkes.go.id/download/ Kebijakan\%20Gizi/PMK\%2075-2013. pdf.

[2] Hoddinott, J., J.R. Behrman, J.A. Maluccio, P. Melgar, A.R. Quisumbing, M. Ramirezzea, et al., 2013. Adult Consequences of Growth Failure in Early Childhood. The American Journal of Clinical Nutrition. 98(5): 1170-1178.

[3] Suharjito, Diana, Yulianto, Ariadi Nugroho. 2017. Mobile Expert System Using Fuzzy Tsukamoto forDiagnosing CattleDisease. 2nd International Conference On Computer Science And Computational Intelligence 2017.

[4] Wiguna, R. Y., Haryanto, H., 2015, Sistem Berbasis Aturan Menggunakan Logika Fuzzy Tsukamoto Untuk Prediksi Jumlah Produksi Roti Pada CV.Gendis Bakery. Skripsi. Fakultas Ilmu Komputer, Universitas Dian Nuswantoro, Semarang.

[5] Maryaningsih, Siswanto, Mesterjon, 2013. Metode Logika Fuzzy Tsukamoto Dalam Sistem Pengambilan Keputusan Penerimaan Beasiswa. Jurnal Media Infotama. 9(1), Hal 140-165.

[6] [Ross, T. J. 2010. Fuzzy Logic With Engineering Applications (3 ed.). United Kingdom: John Wiley \& Sons.

[7] Sutoyo, T. M. 2011. Kecerdasan Buatan. Yogyakarta: C.V Andi Offset (Penerbit Andi).

[8] Arief, M.Rudyanto. 2011. Pemograman WebDinamis Menggunakan PHP dan MySQL. Yogyakarta: Andi Offset.

[9] Arsad RA (2006). Penilaian Status Gizi Anak, Staf Dinas Kesehatan, Kabupaten Polewali Mandar, Medan.

[10] Fidiantoro, Nungki dan Tedy S. 2013. Model Penentuan Status Gizi Balita di Puskesmas. Jurnal Sarjana Teknik Informatika Universitas Ahmad Dahlan. 1 (1) Juni 2013.

[11] Ikhwan Chandra. 2007. Sistem Adminitrasi Puskesmas Rawat Inap Merapi II menggunakan Metode TAS.

[12] Nugroho, Bunafit. 2008. Latihan Membuat Aplikasi Web PHP dan MySQL dengan Dreamweaver $\operatorname{MX}(6,7,2004)$ dan 8. Yogyakarta: Gava Media.

[13] Ogunrinade. 2014. The Incidence of Malnutrition in Children (0-5 Yrs). Journal of Agriculture and Life Science. 1 (2) . Dec 2014.

[14] SCN, 2004. 5th Report on the World Nutrition Situation: Nutrition for Improved Development Outcomes. United Nations System (online), (http://www.unsystem. org/scn/Publications/AnnualMeeting/SCN31/ SCN5Report.pdf) diakses pada tanggal 30 Juli 2018.

[15] Vina Adelina, Dian Eka Ratnawati, M. Ali Fauzi. 2018. Klasifikasi Tingkat Risiko Penyakit Stroke Menggunakan Metode GAFuzzy Tsukamoto. Jurnal Pengembangan Teknologi. 